\title{
(6) OPEN ACCESS \\ Comparing projected impacts of cigarette floor price and excise tax policies on socioeconomic disparities in smoking
}

\author{
Shelley D Golden, ${ }^{1}$ Matthew C Farrelly, ${ }^{2}$ Douglas A Luke, ${ }^{3}$ Kurt M Ribis $1^{1,4}$
}

${ }^{1}$ Gillings School of Global Public Health, University of North Carolina, Chapel Hill, North Carolina, USA

${ }^{2}$ RTI International, Research Triangle Park, North Carolina, USA

${ }^{3}$ Center for Public Health Systems Science, George Warren Brown School of Social Work, Washington University in St. Louis, St. Louis, Missouri, USA

${ }^{4}$ Lineberger Comprehensive Cancer Center, University of North Carolina, Chapel Hill, North Carolina, USA

\section{Correspondence to} Dr Shelley D Golden, Department of Health Behavior, Gillings School of Global Public Health, University of North Carolina, 364 Rosenau Hall, CB7440, Chapel Hill, NC 27599, USA; sgolden@email.unc.edu

Received 3 June 2016 Revised 8 July 2016 Accepted 12 July 2016

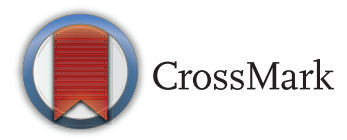

\footnotetext{
To cite: Golden SD, Farrelly MC, Luke DA, et al. Tob Control 2016;25:160i66.
}

\begin{abstract}
Background About half of all US states have cigarette minimum price laws (MPLs) that require a per cent mark-up on prices, but research suggests they may not be very effective in raising prices. An alternative type of MPL sets a floor price below which packs cannot be sold, and may be more promising. This new type of MPL policy has only been implemented in 1 city, therefore its benefits relative to excise taxes is difficult to assess.

Methods We constructed a set of possible state floor price MPL options, and matched them to possible state excise tax hikes designed to produce similar average price increases. Using self-reported price and cigarette consumption data from 23521 participants in the 2010-2011 Tobacco Use Supplement of the Current Population Survey, we projected changes in pack prices and cigarette consumption following implementation of each paired MPL and tax option, for lower and higher income groups.
\end{abstract}

Results We project that state MPLs set at the average reported pack price would raise prices by $\$ 0.33$ and reduce cigarette consumption by about $4 \%$; a tax with a similar average price effect would reduce consumption by $2.3 \%$. MPLs and taxes that raise average prices by more than $\$ 2.00$ would reduce consumption by $15.9 \%$ and $13.5 \%$, respectively. In all models, we project that MPLs will reduce income-based smoking disparities more than their comparable excise taxes.

Conclusions Floor price cigarette MPLs set at or above what consumers currently report paying could reduce both tobacco use and socioeconomic disparities in smoking.

Nearly one in six US adults are current cigarette smokers, ${ }^{1}$ and prevalence is much higher among individuals with low incomes. In 2014, 26.3\% of adults living below the federal poverty level smoked, in comparison to only $15.2 \%$ of those living at or above it. ${ }^{1}$ Increasing the price of tobacco products is one of the most effective strategies for reducing tobacco use,,$^{2}$ and two reviews indicate it shows promise for decreasing socioeconomic disparities. ${ }^{45}$

Cigarette prices have typically been raised in the USA through excise taxes, but recently some states and cities are exploring non-tax price-related policies. $^{6}{ }^{7}$ One approach is a minimum price law (MPL), which sets a minimum price below which it is illegal to sell a specific product. Many MPLs work by requiring per cent mark-ups on retail or manufacturer prices, but evidence of their effectiveness is limited, likely because current mark-ups are small, and many MPLs permit the use of price promotions to undercut the minimum price level. ${ }^{8} 9$ Public health and legal officials recently recommended a style of MPL that sets a single floor price below which cigarettes cannot be sold. ${ }^{10}$ A floor price MPL was implemented in New York City in 2014, and Chicago may implement a similar policy soon.

Excise taxes and floor price MPLs differ in how they are designed to raise tobacco prices. Whereas most cigarette excise taxes in the USA levy a specific price hike across the market, floor price MPLs are structured to raise prices particularly on cheaper products. For instance, a 50-cent tax hike applies to a $\$ 4.00$ discount pack and a $\$ 7.00$ premium brand. In contrast, a $\$ 5.50 \mathrm{MPL}$ should raise the price by $\$ 1.50$ on the discount pack but not alter the premium brand price. As a result, floor price MPLs may have a stronger impact on individuals who smoke discount cigarette brands or use coupons to reduce the price they pay. Greater use of several price minimisation strategies has been documented among low-income smokers. ${ }^{11-13}$

In this study, we test the hypothesis that floor price MPLs may be more effective than excise taxes at reducing tobacco consumption, especially among lower income smokers, by conducting a counterfactual simulation. We construct four pairs of potential state-specific MPL floor prices and excise taxes structured to raise average prices by the same amount. Using nationally representative smoking and self-reported cigarette price data, and previous research about price responsiveness of smokers, ${ }^{14-18}$ we project the impacts of implementing each policy on prices and consumption, among all smokers, and then among higher income and lower income smokers separately.

\section{METHODS \\ Sample}

Our estimates of smoking behaviour and cigarette prices prior to simulated policy implementation derive from adult participants in the 2010-2011 Tobacco Use Supplement (TUS) of the Current Population Survey, a national survey that is sponsored by the National Cancer Institute and administered by the US Census Bureau. ${ }^{19}$ We excluded 58091 proxy respondents who were not eligible to be asked all TUS questions, and an additional 896 respondents with missing smoking status data, resulting in a sample of 170469 respondents.

Of the 170469 eligible participants, 27611 (16.2\%) reported being current smokers, and 23730 had complete data on consumption and price paid for the last pack of cigarettes. 
We excluded 206 individuals who reported paying extremely high $(>\$ 25)$ or low $(<\$ 1)$ cigarette prices, leaving us with a final sample of 23524 .

\section{Measures}

\section{Smoking status}

Individuals were considered smokers if they reported having smoked at least 100 cigarettes in their lifetime, and currently smoking every day or some days.

\section{Consumption}

Using TUS smoker reports of the number of days that they smoke and the number of cigarettes they consume per smoking day, we calculated monthly consumption for each smoker, and divided it by 30 to create a daily consumption variable. If nondaily smokers failed to indicate how many days they smoked, we assumed 14.5 out of 30 , based on previous research. ${ }^{20} 21$

\section{Household income}

To create an approximate measure of whether an individual lives in a household below or above the 2010 median income level of $\$ 50046,,^{22}$ we categorised everyone who reported incomes of \$50 000-\$59 999 or more as higher income and everyone who reported incomes as \$40 000-\$49 999 or less as lower income.

\section{Self-reported prices paid for a pack of cigarettes}

TUS smokers indicated the price they paid for their last pack or carton of cigarettes, after using discounts. If the self-reported price was for a carton, we divided it by 10 to get a per pack price.

\section{Analysis}

Constructing MPL and tax counterfactuals

We first constructed four state-specific MPL floor options that corresponded to $75 \%, 100 \%, 125 \%$ and $150 \%$ of the mean price levels reported by participants buying in each state. To construct corresponding state-specific tax hike levels, we calculated the average price increase we would expect from each MPL using the process to project price changes described below, assuming no evasion, and set the tax hike amounts at these averages.

\section{Projecting changes in cigarette pack prices}

For each potential policy, we projected a new cigarette pack price for each sample member. The extent of illicit tobacco trade in the USA varies by state and region, but a recent national report estimates that between $8.5 \%$ and $21 \%$ of US cigarette sales are illicit. ${ }^{23}$ Averaging these, we drew a random sample of $15 \%$ of respondents and assumed they would evade new price policies and continue to pay their previously self-reported price. We also assumed that anyone who reported buying on an Indian reservation would continue to do so, evading the new law and paying their previous price. Projected prices for MPLs were set at the purchase state floor price level for all non-evading respondents who initially reported paying less than the floor price, and at the respondent's self-reported paid price for everyone who reported paying the new MPL floor price amount or more. Projected prices for excise taxes were determined by adding the tax hike amount to the self-reported price for all non-evading respondents. To examine whether our results were affected by variation in random sampling of evaders, we repeated this process 10 times. Each produced the same consumption estimates once rounded.
Simulating changes in cigarette consumption

We simulated our projections of cigarette consumption following an increase in cigarette prices using previous research on cigarette price elasticity, a measure of the change in quantity of product consumed following a change in price. Previous reviews converge on a consensus elasticity estimate of $-0.4,{ }^{15}{ }^{16}$ but some recent studies have documented smaller elasticities. ${ }^{14} 1718$ We ran one set of models assuming a more conservative elasticity estimate than the consensus $(-0.3)$. There is also discrepancy in previous literature about whether price responsiveness varies by income level. Elasticities from US-based studies range from -0.29 to -0.43 for low-income smokers, and from -0.10 to -0.22 for high-income smokers. ${ }^{24-26}$ We therefore ran each of our models again, using differential elasticities $\left(\mathrm{e}_{\text {high income }}=\right.$ $-0.15 ; \mathrm{e}_{\text {low income }}=-0.35$ ) that were within this range and that produced a weighted average across the sample of approximately -0.3 . We report projected estimates of daily cigarette consumption per population of smokers in the TUS, which comprise changes due to quitting and reduced consumption among continuing smokers.

\section{Estimating the impact of MPLs and taxes on socioeconomic disparities in smoking}

We stratified our results to estimate the price and consumption effects of each policy separately for the TUS populations in lower $(<\$ 50000)$ and higher $(\geq \$ 50000)$ household income categories.

\section{RESULTS}

\section{Smoking and prices}

Nearly 21\% of respondents with household incomes below $\$ 50000$ per year reported smoking at baseline, compared with $11 \%$ of higher income respondents (table 1). Lower income smokers also smoked more frequently, and consumed 0.38 cigarettes more per day (13.34 vs 12.96$)$. The average selfreported prices were $\$ 5.20$ overall, and were $\$ 5.42$ and $\$ 5.10$ among higher and lower income smokers, respectively.

\section{State MPL floor price levels and tax amounts}

State-specific MPL floor prices and tax hike amounts designed to produce the same average price increases in the absence of evasion are provided in table 2. In Missouri, where purchasers reported paying the least for a pack of cigarettes (state mean= \$3.50), we constructed MPL levels ranging from $\$ 2.63$ (75\% of mean) to $\$ 5.25$ (150\% of mean), and tax increases ranging from $\$ 0.10$ to $\$ 1.77$. In New York, where respondents reported the highest prices (state mean=\$7.21), we constructed MPL levels from $\$ 5.41$ to $\$ 10.81$, and tax increases from $\$ 0.71$ to $\$ 3.73$.

\section{Projected price changes}

For each MPL and tax option, we calculated absolute price changes using the difference between respondents' self-reported prices and the projected new prices, and also calculated relative price increases based on the per cent increase in price each respondent would experience. Average absolute price changes for each policy option are listed on the horizontal axis of figure 1 , and the corresponding average relative price increase for each policy, by income group, is charted on the vertical axis. The four MPL counterfactuals are projected to raise absolute prices by $\$ 0.07, \$ 0.35, \$ 1.07$ and $\$ 2.08$, on average. Price changes projected for the corresponding taxes were very similar $(\$ 0.09, \$ 0.36, \$ 1.12, \$ 2.13)$. The slightly higher price increases 
Table 1 Smoking behaviours reported by TUS participants

\begin{tabular}{|c|c|c|c|c|c|c|}
\hline & \multicolumn{2}{|l|}{ All } & \multicolumn{2}{|c|}{ Lower income } & \multicolumn{2}{|c|}{ Higher income } \\
\hline & n/mean & Per cent/SD & n/mean & Per cent/SD & n/mean & Per cent/SD \\
\hline Total TUS sample & 170469 & - & 89293 & - & 81176 & - \\
\hline Non-smokers & 142858 & $83.8 \%$ & 70740 & $79.2 \%$ & 72118 & $88.8 \%$ \\
\hline Smokers & 27611 & $16.2 \%$ & 18553 & $20.8 \%$ & 9058 & $11.2 \%$ \\
\hline Analytic sample of smokers & 23524 & - & 15803 & - & 7721 & - \\
\hline \multicolumn{7}{|l|}{ Smoking frequency } \\
\hline Every day & 19283 & $82.0 \%$ & 13081 & $82.8 \%$ & 13081 & $19.7 \%$ \\
\hline Some days & 5640 & $18.0 \%$ & 2722 & $17.2 \%$ & 1519 & $80.3 \%$ \\
\hline Number of cigarettes smoked per day & 13.21 & 9.02 & 13.34 & 9.07 & 12.96 & 8.92 \\
\hline Self-reported price paid for last pack & $\$ 5.20$ & 1.71 & $\$ 5.10$ & 1.74 & $\$ 5.42$ & 1.65 \\
\hline
\end{tabular}

under the tax result from evaders saving less by avoiding the tax than by avoiding the MPL. From an original self-reported price of $\$ 5.20$, the MPLs and taxes we simulated are therefore projected to produce new average prices ranging from $\$ 5.27$ to $\$ 7.33$.

Relative price increases range from $4.2 \%$ to $51.3 \%$ for lower income smokers as the MPL level rises. Among higher income smokers, these same MPLs produce relative price increases of only $2.2-43.8 \%$. Relative price increases for taxes are similar for both income groups, and closely approximate what is observed for higher income smokers with an MPL.

\section{Projected consumption changes}

We next calculated changes in consumption derived from the relative price increases consumers are projected to experience. Estimates of changes in consumption for the entire population do not differ substantially under the two price sensitivity scenarios we considered, so we report results for the models that assume a consistent elasticity of -0.3 . As MPLs increase across the four options, we predict that per capita daily consumption would drop from 13.2 cigarettes to $13.0,12.7,12.0$ and 11.1 cigarettes. The corresponding tax policies are projected to produce consumption levels of 13.1, 12.9, 12.3 and 11.4 cigarettes, respectively. Put in relative terms, we project that an MPL that raises average prices by $\$ 0.33$ would reduce consumption by nearly $4 \%$, whereas the $\$ 0.37$ tax increase only reduces consumption by $2.3 \%$. Larger average price increases of more than $\$ 2.00$ are projected to result in a $15.9 \%$ drop in consumption for an MPL, and $13.5 \%$ for a tax.

Figure 2 contains two panels that chart projected changes in per capita cigarette consumption by income group. Both MPLs and taxes are projected to reduce income-based disparities in consumption among TUS smokers, but gaps shrink more for MPLs than for taxes. In the TUS, daily consumption averages were 0.38 cigarettes more among lower income smokers than higher income smokers. Under assumptions of consistent price sensitivity (panel A), we predict that this gap shrinks to 0.15 cigarettes when MPLs raise prices by $\$ 0.33$, but only to 0.35 cigarettes when taxes raise prices by $\$ 0.37$. At the highest price increase options we modelled, the MPL eliminates the consumption gap, whereas the tax reduces it to 0.22 cigarettes per day. Income-based disparities contract further if we assume that lower income is associated with greater price sensitivity (panel B), but the relative impact of MPLs versus taxes on disparities remains. In this case, we predict that even an MPL set at a state mean could eliminate the average consumption difference between lower and higher income smokers, whereas under a similar tax the difference shrinks to 0.15 cigarettes. At high MPL and tax levels, both policies reverse the consumption gap.

\section{DISCUSSION}

This study is the first analysis designed to quantify the potential impact of cigarette MPLs on smoking consumption, and compare that to what we might expect from a tax increase designed to raise average prices by the same amount. Our results indicate that floor price MPLs that raise the cheapest price one can pay for cigarettes can reduce overall consumption more than comparable taxes. For example, an MPL that raises prices by $\$ 0.33$ on average produced a $4 \%$ decline in consumption in our models, compared with a $2.3 \%$ decline in consumption from a tax that raises prices by $\$ 0.37$. An MPL that produced a price increase of more than $\$ 2.00$ was projected to result in a $16 \%$ decline in consumption, compared with a $13.5 \%$ drop for a corresponding tax increase.

Furthermore, our results indicate that while both policies might reduce income-based smoking disparities, MPLs may have more potential as proequity tobacco control policies. At every MPL and comparable tax level we modelled, MPLs produced larger consumption reductions among lower income smokers than taxes did. If lower income smokers are more price sensitive than higher income smokers, even a relatively low MPL set at the average price reported by cigarette buyers in a state could eliminate the per capita consumption gap. To achieve a similar outcome, a tax would need to raise average prices by almost twice as much.

The prices that TUS smokers report paying shed light on why we observe these results. Economic theory predicts that consumer responses to price changes depend on the amount of the price increase relative to the original price paid. ${ }^{15}$ Lower income smokers in the TUS reported paying an average of $\$ 0.32$ less for a pack of cigarettes compared with higher income smokers. Any price policy, even a tax that levies the same specific price hike on all smokers, reduces smoking more among the people previously paying the least, because the increase is relatively larger on cheaper prices. Consumption should decline more among people originally paying that rate. An MPL, however, also produces a larger absolute price increase on those smokers previously paying the least, which in turn produces an even higher relative price hike. Our results reflect this; at all price policy levels, relative price changes were substantially higher for lower income smokers under the MPL policy than 
Table 2 MPL level and tax rate options by state

\begin{tabular}{|c|c|c|c|c|c|c|c|c|}
\hline & \multicolumn{2}{|c|}{$\begin{array}{l}\text { Option 1: MPL=75\% } \\
\text { of state mean }\end{array}$} & \multicolumn{2}{|c|}{$\begin{array}{l}\text { Option 2: MPL=100\% } \\
\text { of state mean }\end{array}$} & \multicolumn{2}{|c|}{$\begin{array}{l}\text { Option } 3: \mathrm{MPL}=125 \% \\
\text { of state mean }\end{array}$} & \multicolumn{2}{|c|}{$\begin{array}{l}\text { Option } 4: \mathrm{MPL}=150 \% \\
\text { of state mean }\end{array}$} \\
\hline & MPL level & Tax increase & MPL level & Tax increase & MPL level & Tax increase & MPL level & Tax increase \\
\hline Alabama & $\$ 3.22$ & $\$ 0.04$ & $\$ 4.29$ & $\$ 0.37$ & $\$ 5.37$ & $\$ 1.14$ & $\$ 6.44$ & $\$ 2.19$ \\
\hline Alaska & $\$ 5.51$ & $\$ 0.10$ & $\$ 7.34$ & $\$ 0.54$ & $\$ 9.18$ & $\$ 1.89$ & $\$ 11.02$ & $\$ 3.69$ \\
\hline Arizona & $\$ 4.22$ & $\$ 0.20$ & $\$ 5.63$ & $\$ 0.64$ & $\$ 7.03$ & $\$ 1.54$ & $\$ 8.44$ & $\$ 2.84$ \\
\hline Arkansas & $\$ 3.59$ & $\$ 0.08$ & $\$ 4.79$ & $\$ 0.42$ & $\$ 5.99$ & $\$ 1.26$ & $\$ 7.19$ & $\$ 2.42$ \\
\hline California & $\$ 3.88$ & $\$ 0.08$ & $\$ 5.18$ & $\$ 0.43$ & $\$ 6.47$ & $\$ 1.39$ & $\$ 7.76$ & $\$ 2.64$ \\
\hline Colorado & $\$ 3.59$ & $\$ 0.04$ & $\$ 4.79$ & $\$ 0.34$ & $\$ 5.99$ & $\$ 1.24$ & $\$ 7.19$ & $\$ 2.41$ \\
\hline Connecticut & $\$ 5.52$ & $\$ 0.12$ & $\$ 7.36$ & $\$ 0.46$ & $\$ 9.20$ & $\$ 1.86$ & $\$ 11.03$ & $\$ 3.68$ \\
\hline Delaware & $\$ 3.74$ & $\$ 0.06$ & $\$ 4.99$ & $\$ 0.33$ & $\$ 6.23$ & $\$ 1.26$ & $\$ 7.48$ & $\$ 2.49$ \\
\hline District of Columbia & $\$ 5.05$ & $\$ 0.10$ & $\$ 6.74$ & $\$ 0.47$ & $\$ 8.42$ & $\$ 1.71$ & $\$ 10.11$ & $\$ 3.37$ \\
\hline Florida & $\$ 3.62$ & $\$ 0.10$ & $\$ 4.82$ & $\$ 0.48$ & $\$ 6.03$ & $\$ 1.31$ & $\$ 7.23$ & $\$ 2.45$ \\
\hline Georgia & $\$ 3.15$ & $\$ 0.05$ & $\$ 4.20$ & $\$ 0.35$ & $\$ 5.25$ & $\$ 1.10$ & $\$ 6.29$ & $\$ 2.11$ \\
\hline Hawaii & $\$ 5.41$ & $\$ 0.14$ & $\$ 7.21$ & $\$ 0.59$ & $\$ 9.01$ & $\$ 1.88$ & $\$ 10.81$ & $\$ 3.61$ \\
\hline Idaho & $\$ 3.19$ & $\$ 0.05$ & $\$ 4.26$ & $\$ 0.36$ & $\$ 5.32$ & $\$ 1.10$ & $\$ 6.39$ & $\$ 2.13$ \\
\hline Illinois & $\$ 3.92$ & $\$ 0.07$ & $\$ 5.22$ & $\$ 0.48$ & $\$ 6.53$ & $\$ 1.50$ & $\$ 7.84$ & $\$ 2.68$ \\
\hline Indiana & $\$ 3.44$ & $\$ 0.07$ & $\$ 4.58$ & $\$ 0.35$ & $\$ 5.73$ & $\$ 1.17$ & $\$ 6.88$ & $\$ 2.30$ \\
\hline lowa & $\$ 3.81$ & $\$ 0.13$ & $\$ 5.08$ & $\$ 0.43$ & $\$ 6.35$ & $\$ 1.34$ & $\$ 7.62$ & $\$ 2.55$ \\
\hline Kansas & $\$ 3.42$ & $\$ 0.18$ & $\$ 4.56$ & $\$ 0.54$ & $\$ 5.70$ & $\$ 1.31$ & $\$ 6.84$ & $\$ 2.38$ \\
\hline Kentucky & $\$ 2.90$ & $\$ 0.07$ & $\$ 3.87$ & $\$ 0.39$ & $\$ 4.83$ & $\$ 1.04$ & $\$ 5.80$ & $\$ 1.95$ \\
\hline Louisiana & $\$ 3.26$ & $\$ 0.05$ & $\$ 4.34$ & $\$ 0.35$ & $\$ 5.43$ & $\$ 1.13$ & $\$ 6.51$ & $\$ 2.19$ \\
\hline Maine & $\$ 4.46$ & $\$ 0.16$ & $\$ 5.94$ & $\$ 0.51$ & $\$ 7.43$ & $\$ 1.55$ & $\$ 8.91$ & $\$ 3.01$ \\
\hline Maryland & $\$ 4.46$ & $\$ 0.08$ & $\$ 5.94$ & $\$ 0.39$ & $\$ 7.43$ & $\$ 1.50$ & $\$ 8.91$ & $\$ 2.97$ \\
\hline Massachusetts & $\$ 5.42$ & $\$ 0.14$ & $\$ 7.23$ & $\$ 0.58$ & $\$ 9.04$ & $\$ 1.90$ & $\$ 10.85$ & $\$ 3.68$ \\
\hline Michigan & $\$ 4.22$ & $\$ 0.23$ & $\$ 5.63$ & $\$ 0.52$ & $\$ 7.03$ & $\$ 1.48$ & $\$ 8.44$ & $\$ 2.86$ \\
\hline Minnesota & $\$ 3.89$ & $\$ 0.07$ & $\$ 5.19$ & $\$ 0.33$ & $\$ 6.48$ & $\$ 1.34$ & $\$ 7.78$ & $\$ 2.62$ \\
\hline Mississippi & $\$ 3.27$ & $\$ 0.06$ & $\$ 4.36$ & $\$ 0.35$ & $\$ 5.44$ & $\$ 1.12$ & $\$ 6.53$ & $\$ 2.19$ \\
\hline Missouri & $\$ 2.63$ & $\$ 0.10$ & $\$ 3.50$ & $\$ 0.42$ & $\$ 4.38$ & $\$ 0.98$ & $\$ 5.25$ & $\$ 1.77$ \\
\hline Montana & $\$ 4.09$ & $\$ 0.05$ & $\$ 5.45$ & $\$ 0.33$ & $\$ 6.82$ & $\$ 1.37$ & $\$ 8.18$ & $\$ 2.73$ \\
\hline Nebraska & $\$ 3.31$ & $\$ 0.07$ & $\$ 4.41$ & $\$ 0.40$ & $\$ 5.52$ & $\$ 1.15$ & $\$ 6.62$ & $\$ 2.21$ \\
\hline Nevada & $\$ 3.53$ & $\$ 0.10$ & $\$ 4.70$ & $\$ 0.45$ & $\$ 5.88$ & $\$ 1.31$ & $\$ 7.05$ & $\$ 2.42$ \\
\hline New Hampshire & $\$ 4.11$ & $\$ 0.07$ & $\$ 5.48$ & $\$ 0.40$ & $\$ 6.84$ & $\$ 1.41$ & $\$ 8.21$ & $\$ 2.74$ \\
\hline New Jersey & $\$ 5.31$ & $\$ 0.15$ & $\$ 7.08$ & $\$ 0.47$ & $\$ 8.85$ & $\$ 1.81$ & $\$ 10.62$ & $\$ 3.55$ \\
\hline New Mexico & $\$ 4.01$ & $\$ 0.23$ & $\$ 5.34$ & $\$ 0.69$ & $\$ 6.68$ & $\$ 1.62$ & $\$ 8.02$ & $\$ 2.88$ \\
\hline New York & $\$ 5.41$ & $\$ 0.71$ & $\$ 7.21$ & $\$ 1.33$ & $\$ 9.01$ & $\$ 2.31$ & $\$ 10.81$ & $\$ 3.73$ \\
\hline North Carolina & $\$ 3.14$ & $\$ 0.06$ & $\$ 4.18$ & $\$ 0.38$ & $\$ 5.23$ & $\$ 1.10$ & $\$ 6.27$ & $\$ 2.11$ \\
\hline North Dakota & $\$ 3.11$ & $\$ 0.06$ & $\$ 4.15$ & $\$ 0.34$ & $\$ 5.19$ & $\$ 1.10$ & $\$ 6.23$ & $\$ 2.12$ \\
\hline Ohio & $\$ 3.77$ & $\$ 0.08$ & $\$ 5.02$ & $\$ 0.35$ & $\$ 6.28$ & $\$ 1.29$ & $\$ 7.53$ & $\$ 2.52$ \\
\hline Oklahoma & $\$ 3.36$ & $\$ 0.09$ & $\$ 4.49$ & $\$ 0.43$ & $\$ 5.61$ & $\$ 1.19$ & $\$ 6.73$ & $\$ 2.26$ \\
\hline Oregon & $\$ 3.64$ & $\$ 0.06$ & $\$ 4.86$ & $\$ 0.34$ & $\$ 6.07$ & $\$ 1.26$ & $\$ 7.29$ & $\$ 2.44$ \\
\hline Pennsylvania & $\$ 4.07$ & $\$ 0.08$ & $\$ 5.43$ & $\$ 0.43$ & $\$ 6.79$ & $\$ 1.43$ & $\$ 8.15$ & $\$ 2.76$ \\
\hline Rhode Island & $\$ 5.57$ & $\$ 0.25$ & $\$ 7.42$ & $\$ 0.56$ & $\$ 9.28$ & $\$ 1.88$ & $\$ 11.13$ & $\$ 3.72$ \\
\hline South Carolina & $\$ 3.04$ & $\$ 0.06$ & $\$ 4.05$ & $\$ 0.38$ & $\$ 5.06$ & $\$ 1.05$ & $\$ 6.08$ & $\$ 2.03$ \\
\hline South Dakota & $\$ 4.01$ & $\$ 0.09$ & $\$ 5.35$ & $\$ 0.36$ & $\$ 6.69$ & $\$ 1.36$ & $\$ 8.03$ & $\$ 2.68$ \\
\hline Tennessee & $\$ 3.03$ & $\$ 0.02$ & $\$ 4.04$ & $\$ 0.35$ & $\$ 5.05$ & $\$ 1.06$ & $\$ 6.06$ & $\$ 2.03$ \\
\hline Texas & $\$ 3.98$ & $\$ 0.10$ & $\$ 5.31$ & $\$ 0.43$ & $\$ 6.63$ & $\$ 1.38$ & $\$ 7.96$ & $\$ 2.68$ \\
\hline Utah & $\$ 4.01$ & $\$ 0.09$ & $\$ 5.34$ & $\$ 0.46$ & $\$ 6.68$ & $\$ 1.41$ & $\$ 8.02$ & $\$ 2.68$ \\
\hline Vermont & $\$ 5.05$ & $\$ 0.10$ & $\$ 6.73$ & $\$ 0.47$ & $\$ 8.42$ & $\$ 1.74$ & $\$ 10.10$ & $\$ 3.40$ \\
\hline Virginia & $\$ 3.16$ & $\$ 0.08$ & $\$ 4.21$ & $\$ 0.40$ & $\$ 5.26$ & $\$ 1.13$ & $\$ 6.31$ & $\$ 2.13$ \\
\hline Washington & $\$ 5.33$ & $\$ 0.31$ & $\$ 7.10$ & $\$ 0.83$ & $\$ 8.88$ & $\$ 2.01$ & $\$ 10.65$ & $\$ 3.71$ \\
\hline West Virginia & $\$ 2.88$ & $\$ 0.02$ & $\$ 3.84$ & $\$ 0.30$ & $\$ 4.80$ & $\$ 1.01$ & $\$ 5.76$ & $\$ 1.93$ \\
\hline Wisconsin & $\$ 4.81$ & $\$ 0.08$ & $\$ 6.41$ & $\$ 0.42$ & $\$ 8.01$ & $\$ 1.62$ & $\$ 9.61$ & $\$ 3.20$ \\
\hline Wyoming & $\$ 3.29$ & $\$ 0.05$ & $\$ 4.39$ & $\$ 0.37$ & $\$ 5.48$ & $\$ 1.14$ & $\$ 6.58$ & $\$ 2.19$ \\
\hline Average & $\$ 3.90$ & $\$ 0.11$ & $\$ 5.20$ & $\$ 0.46$ & $\$ 6.50$ & $\$ 1.38$ & $\$ 7.80$ & $\$ 2.63$ \\
\hline
\end{tabular}

MPL, minimum price law. 
Figure 1 Relative price increases income. API, average price increase; $\mathrm{MPL}$, minimum price law. projected for each policy option by

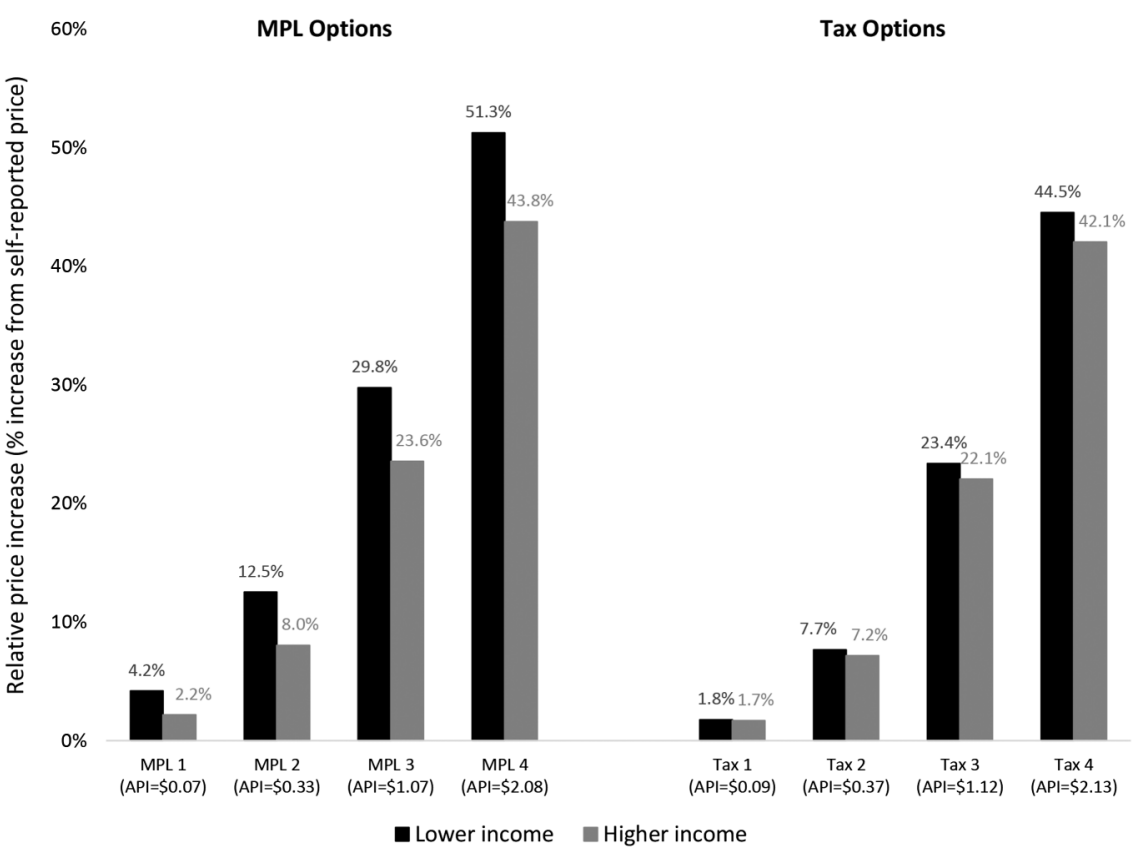

they were for higher income smokers under the MPL, or any smokers under the tax. In addition, the initial \$0.32 difference in average prices reported by lower versus higher income smokers drops to \$0.23-\$0.26 for MPLs set at state mean prices or above, but remains relatively constant under all tax options (results not shown).

We modelled total change in cigarette consumption, which likely occurs from some people reducing the amount they smoke, as well as others quitting smoking altogether. In the TUS, smoking prevalence was nearly twice as high among lower income respondents than higher income respondents. Although the policies we model reduced or even eliminated the per capita cigarette consumption disparity among smokers, the original prevalence disparity would likely shrink but not disappear. Assuming consistent price elasticity, MPLs set at the mean state price are projected to reduce per capita daily consumption among the 15803 lower income smokers by 0.60 cigarettes per day and among the 7721 higher income smokers by 0.37 cigarettes. The parallel tax projections are 0.32 and 0.29 , respectively. Based on original daily consumption averages of 13.34 (lower income) and 12.96 (higher income), and previous studies that suggest that about one-half of reductions in total cigarette consumption result from smokers quitting all together, ${ }^{25} 2728$ it could be reasonable to expect about $2.2 \%$ of lower income smokers and $1.4 \%$ of higher income smokers to quit in the MPL scenario, compared with $1.1 \%$ of smokers from each income group in the tax scenario. This translates to 466 TUS smokers quitting under the MPL, compared with only 264 under the tax.

In addition to their promise for shrinking disparities, floor price MPLs may have other advantages as price policies. Many of the MPLs currently adopted in US states employ complex mark-up schemes, rather than a floor price, and permit discounting. ${ }^{8}$ As a result, these MPLs appear ineffective at raising prices, and are likely difficult to enforce because the legal allowable price is not simple to discern. Floor prices, in contrast, are more straightforward, which simplifies enforcement and limits illicit trade. Yet, MPLs also have some drawbacks. For those low-income smokers who maintain their consumptions levels, pricing policies add financial strain to their budgets, and this strain is the greatest for those who experience a large relative price increase, as is more likely under an MPL. Smokers may want to quit rather than face these costs, but have a particularly difficult time doing so. ${ }^{29} 30$ Another potential downside of MPLs is that they may raise profits for the tobacco industry that could be shifted to marketing or other efforts to grow their consumer base. ${ }^{6}$

A comprehensive approach to tobacco pricing policy that relies on excise taxes and floor price MPLs may be the strongest approach. Combining MPLs with tax policies may ensure that prices are raised on premium products as well as discount brands, while maintaining the disproportionate effect at the cheaper end of the market we find to be associated with reducing disparities. Furthermore, if MPLs are implemented with high excise taxes that are included in the minimum price level, the 'profits' from the MPL could go to state governments in the form of taxes. This approach is similar to two policies considered in other countries, but less familiar to policymakers in the USA: a minimum specific excise tax which disproportionately raises taxes on cheaper products, ${ }^{31} 32$ and a price cap and tax policy that sets a maximum price a retailer can charge and adds a large excise tax to raise consumer prices. ${ }^{33}$ Finally, pairing both MPLs and taxes with provision of accessible, free or low-cost cessation services may enhance the effectiveness of the policy, and minimise the extent to which it places additional burdens on already vulnerable groups. ${ }^{34}$

As with any predictive modelling, our results are heavily dependent on the assumptions we employ. In particular, we assume that $15 \%$ of smokers will respond to increased prices by seeking out opportunities to avoid the new prices. MPL price analyses in Malaysia ${ }^{35}$ and New York City, ${ }^{36}$ however, indicate that the per cent of illicit (or below minimum price) sales only increased by 3-5 percentage points following policy implementation, suggesting we may have underestimated the modelled policies' impact on prices. In reality, the amount of policy avoidance will likely vary by state, based in part on differences in prices in, and distances to, nearby cigarette markets, ${ }^{37} 38$ and by income levels, smoking intensity and self-reported price levels prepolicy. The people likely to be more deeply affected by an MPL than by a tax (those paying and earning the least) may also 

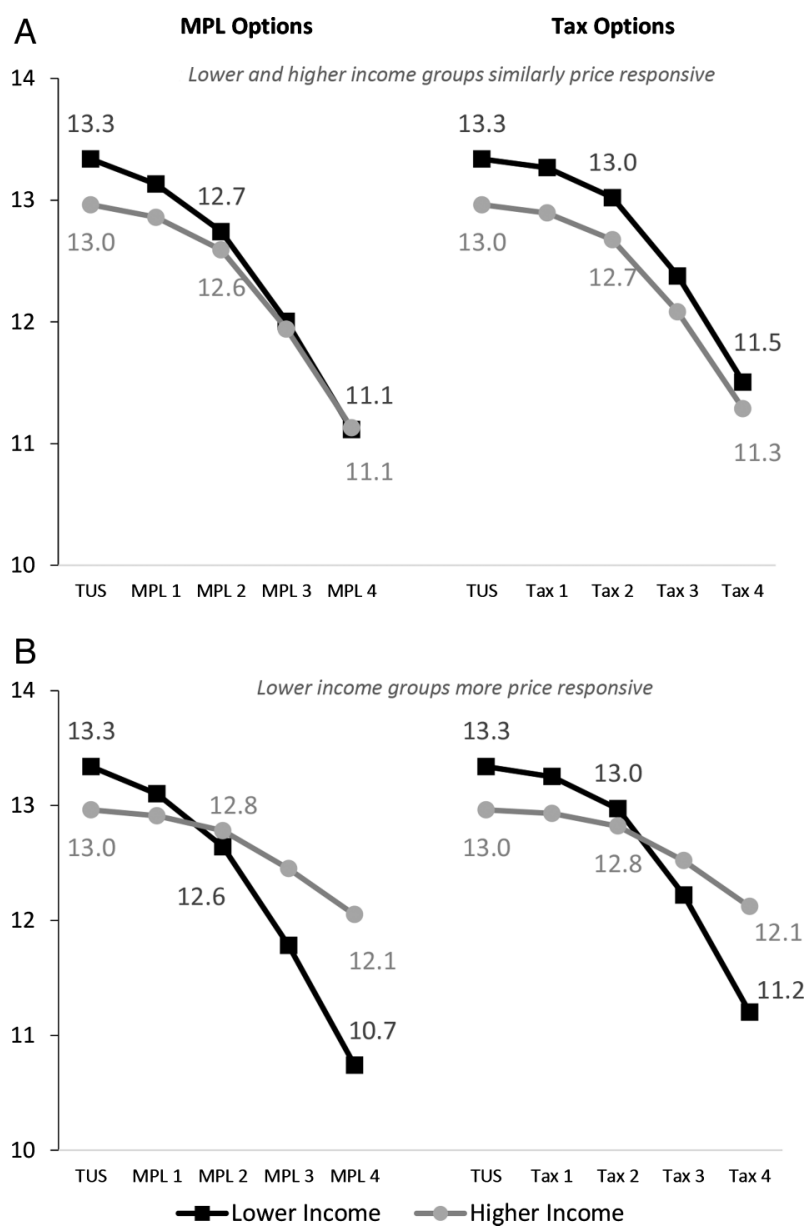

Figure 2 Projected changes in per capita daily cigarette consumption by income. MPL, minimum price law; TUS, Tobacco Use Supplement.

be more motivated to evade an MPL than a tax, which might diminish the relative impact of the MPL. Finally, we focus this analysis on cigarette consumption, but it is possible that changes in cigarette prices following MPLs or taxes could prompt smokers to switch to another tobacco product, like little cigars ${ }^{39}$ or e-cigarettes, ${ }^{40}$ or use loose tobacco, ${ }^{41}$ rather than quit or reduce tobacco use.

In addition to these assumptions about consumers, our modelling does not account for how retailers or the industry might respond to an MPL or tax. Empirical research, as well as economic theories of price setting in oligopolistic markets, indicates that the industry either overshifts all of its taxes, so that all prices go up by more than the tax amount, ${ }^{42}$ or primarily shifts a tax burden to premium products, raising prices on those products disproportionately in order to keep the prices of discount brands cheap. ${ }^{15}$ 44-46 If the excise taxes we analysed were overshifted across all products, we may have underestimated the rise in prices for all products and the associated reductions in overall consumption for this policy. If, however, taxes were disproportionately shifted for higher priced products, we may have underestimated the rise in prices on expensive products, but actually overestimated the rise in prices on cheap purchases. In this scenario, we might observe a smaller tax-associated reduction in income-based disparities than modelled. Whether price shifting would occur with an MPL, and how, is unknown. By its nature, an MPL prevents the industry from keeping low-priced products cheap. If the industry generates sufficient profits on these products to offset losses due to reduced consumption generated by the MPL, the incentive to price shift at all may be more limited than under a tax scenario. If an MPL is levied in conjunction with an excise tax, however, the industry might still raise prices on premium products. Researchers should collect empirical data about product-specific price shifts in jurisdictions that have implemented a floor price MPL to build dynamic models of the potential impact of MPLs in a tobacco market system. 4748

Although specific excise taxes have long been the price policy of choice in the USA, the analyses we present here suggest that a floor price style of MPL may be more effective at reducing cigarette consumption, especially among low-income smokers. Specifically, our results indicate that flat rate state MPLs, if set at or above the average pack price reported by smokers in that state, can reduce smoker's cigarette consumption by $67 \%$ more than corresponding taxes. By specifically targeting cheap prices more frequently reported by low-income smokers, MPLs may also be well positioned to reduce income-based smoking disparities, especially if implemented in conjunction with other price policies and low-cost cessation services.

\section{What this paper adds}

Previous research on relatively weak or poorly structured minimum price laws (MPLs) may not reveal their potential as tobacco control strategies. Using nationally representative data about smoking behaviour and prices smokers report paying for cigarettes, this study projects the impact that stronger MPLs could have on prices and cigarette consumption, and compares them to excise taxes designed to raise average prices by similar amounts. Contrary to the limited previous work indicating weak associations between existing MPLs and prices, we predict that MPLs with floor prices set at or above average state prices could reduce disparities in the prices low-income and high-income smokers report paying for cigarettes, as well as the cigarettes they consume, and shows promise as a proequity tobacco control policy.

Contributors SDG conceived the study idea, conducted primary analyses and drafted the final paper. MCF, DAL and KMR assisted with analyses, provided input into the interpretation and discussion of the results, and edited manuscript drafts. All authors reviewed and approved the final version of the manuscript.

Funding National Cancer Institute. Grant number U01 CA154281.

Competing interests KMR is the Chair of the Board of Directors of Counter Tools (http://countertools.org), a non-profit from which he receives compensation. Counter Tools provides technical assistance on point of sale tobacco control issues and distributes store mapping and store audit tools. KMR also has a royalty interest in a store mapping and audit system owned by the University of North Carolina at Chapel Hill but these systems were not used in this study.

Provenance and peer review Not commissioned; externally peer reviewed.

Data sharing statement This study is based on publicly available data.

Open Access This is an Open Access article distributed in accordance with the Creative Commons Attribution Non Commercial (CC BY-NC 4.0) license, which permits others to distribute, remix, adapt, build upon this work non-commercially, and license their derivative works on different terms, provided the original work is properly cited and the use is non-commercial. See: http://creativecommons.org/ licenses/by-nc/4.0/

\section{REFERENCES}

1 Jamal $\mathrm{AH}$, David $\mathrm{M}, \mathrm{O}^{\prime}$ Connor $\mathrm{E}$, et al. Current cigarette smoking among adults_-United States, 2005-2014. MMWR Morb Mortal Wkly Rep 2015;64:1233-40. 
2 Contreary KA, Chattopadhyay SK, Hopkins DP, et al. Economic impact of tobacco price increases through taxation: a community guide systematic review. Am J Prev Med 2015;49:800-8.

3 Chaloupka FJ, Straif K, Leon ME. Effectiveness of tax and price policies in tobacco control. Tob Control 2011;20:235-8.

4 Brown T, Platt $\mathrm{S}$, Amos $\mathrm{A}$. Equity impact of interventions and policies to reduce smoking in youth: systematic review. Tob Control 2014;23:e98-105.

5 Hill S, Amos A, Clifford D, et al. Impact of tobacco control interventions on socioeconomic inequalities in smoking: review of the evidence. Tob Control 2014;23:e89-97.

6 Golden SD, Smith MH, Feighery EC, et al. Beyond excise taxes: a systematic review of literature on non-tax policy approaches to raising tobacco product prices. Tob Control 2016;25:377-85.

7 Lange T, Hoefges M, Ribisl KM. Regulating tobacco product advertising and promotions in the retail environment: a roadmap for states and localities. J Law Med Ethics 2015;43:878-96.

8 Tynan MA, Ribisl KM, Loomis BR. Impact of cigarette minimum price laws on the retail price of cigarettes in the USA. Tob Control 2013;22:e78-85.

9 Feighery EC, Ribisl KM, Schleicher NC, et al. How do minimum cigarette price laws affect cigarette prices at the retail level? Tob Control 2005;14:80-5.

10 McLaughlin I, Pearson A, Laird-Metke E, et al. Reducing tobacco use and access through strengthened minimum price laws. Am J Public Health 2014;104:1844-50.

11 Cornelius ME, Driezen P, Fong GT, et al. Trends in the use of premium and discount cigarette brands: findings from the ITC US Surveys (2002-2011). Tob Control 2014;23(Suppl 1):i48-53.

12 Xu X, Wang X, Caraballo RS. Is every smoker interested in price promotions? An evaluation of price-related discounts by cigarette brands. J Public Health Manag Pract 2016;22:20-8.

13 Xu X, Pesko MF, Tynan MA, et al. Cigarette price-minimization strategies by U.S. smokers. Am J Prev Med 2013;44:472-6.

14 Callison K, Kaestner R. Do higher tobacco taxes reduce adult smoking? New evidence of the effect of recent cigarette tax increases on adult smoking. Econ Inq 2014;52:155-72.

15 Chaloupka FJ, Warner KE. The economics of smoking. Handb Health Econ 2000;1:1539-627.

16 Gallet CA, List JA. Cigarette demand: a meta-analysis of elasticities. Health Econ 2003;12:821-35.

17 Maclean JC, Kessler AS, Kenkel DS. Cigarette taxes and older adult smoking: evidence from the health and retirement study. Health Econ 2015;4:424-38.

18 Tauras JA. Smoke-free air laws, cigarette prices, and adult cigarette demand. Econ Inq 2006;44:333-42.

19 US Department of Commerce, C.B. National Cancer Institute-sponsored Tobacco Use Supplement to the Current Population Survey (2010-11). 2012. http://appliedresearch.cancer.gov/tus-cps/. Data files and technical documentation. http://thedataweb.rm.census.gov/ftp/cps_ftp.html\#cpssupps

20 ScheuermannTS, Mburu WE, Mathur $C$, et al. Correlates of converted and native nondaily smoking. Nicotine Tob Res 2015;17:1112-19.

21 Hassmiller KM, Warner KE, Mendez D, et al. Nondaily smokers: who are they? Am J Public Health 2003:93:1321-7.

22 Noss A. Household income for states: 2009 and 2010. US Department of Commerce, Economics and Statistics Administration, US Census Bureau, 2011.

23 National Research Council. Understanding the U.S. Illicit Tobacco Market: characteristics, policy context, and lessons from international experiences. Washington DC: The National Academies Press, 2015.

24 Colman GJ, Remler DK. Vertical equity consequences of very high cigarette tax increases: If the poor are the ones smoking, how could cigarette tax increases be progressive? J Policy Anal Manage 2008;27:376-400.

25 Farrelly MC, Bray JW, Pechacek T, et al. Response by adults to increases in cigarette prices by sociodemographic characteristics. South Econ J 2001;68:156-65.
26 Centers for Disease Control and Prevention (CDC). Response to increases in cigarette prices by race/ethnicity, income, and age groups-United States, 19761993. MMWR Morb Mortal Wkly Rep 1998;47:605-9.

27 Lewit EM, Coate D. The potential for using excise taxes to reduce smoking. I Health Econ 1982;1:121-45.

28 Chaloupka FJ, Yurekli A, Fong GT. Tobacco taxes as a tobacco control strategy. Tob Control 2012;21:172-80.

29 Kendzor DE, Businelle MS, Costello TJ, et al. Financial strain and smoking cessation among racially/ethnically diverse smokers. Am J Public Health 2010;100:702-6.

30 Siahpush $\mathrm{M}$, Yong $\mathrm{HH}$, Borland $\mathrm{R}$, et al. Smokers with financial stress are more likely to want to quit but less likely to try or succeed: findings from the International Tobacco Control (ITC) Four Country Survey. Addiction 2009;104:1382-90.

31 World Health Organization. WHO technical manual on tobacco tax administration. World Health Organization, 2010.

32 Chaloupka FJ, Kostova D, Shang C. Cigarette excise tax structure and cigarette prices: evidence from the Global Adult Tobacco Survey and the US National Adult Tobacco Survey. Nicotine Tob Res 2014;16:S3-9.

33 Gilmore $A B$, Branston JR, Sweanor D. The case for OFSMOKE: how tobacco price regulation is needed to promote the health of markets, government revenue and the public. Tob Control 2010;19:423-30.

34 Frohlich KL, Potvin L. Transcending the known in public health practice: the inequality paradox: the population approach and vulnerable populations. Am J Public Health 2008;98:216-21.

35 Liber $\mathrm{AC}$, Ross $\mathrm{H}$, Omar $\mathrm{M}$, et al. The impact of the Malaysian minimum cigarette price law: findings from the ITC Malaysia Survey. Tob Control 2015;24(Suppl 3): iii83-7.

36 Silver D, Macinko J, Giorgio $M$, et al. Retailer compliance with tobacco control laws in New York City before and after raising the minimum legal purchase age to 21 . Tob Control Published Online First: 19 Nov 2015. doi:10.1136/tobaccocontrol2015-052547

37 DeCicca P, Kenkel D, Liu F. Excise tax avoidance: the case of state cigarette taxes. $J$ Health Econ 2013;32:1130-41.

38 Hyland A, Bauer JE, Li Q, et al. Higher cigarette prices influence cigarette purchase patterns. Tob Control 2005;14:86-92.

39 Gammon DG, Loomis BR, Dench DL, et al. Effect of price changes in little cigars and cigarettes on little cigar sales: USA, Q4 2011-Q4 2013. Tob Control 2016:25:538-44.

40 Grace RC, Kivell BM, Laugesen M. Estimating cross-price elasticity of e-cigarettes using a simulated demand procedure. Nicotine Tob Res 2015;17:592-8.

41 White JS, Ross H. Smokers' strategic responses to sin taxes: evidence from panel data in Thailand. Health Econ 2015;24:127-41.

42 Keeler TE, Hu TW, Barnett PG, et al. Do cigarette producers price-discriminate by state? An empirical analysis of local cigarette pricing and taxation. J Health Econ 1996;15:499-512.

43 Brock B, Choi K, Boyle RG, et al. Tobacco product prices before and after a statewide tobacco tax increase. Tob Control 2016;25:166-73.

44 Marsh L, Cameron C, Quigg R, et al. The impact of an increase in excise tax on the retail price of tobacco in New Zealand. Tob Control 2016;25:458-63.

45 Brock B, Schillo BA, Moilanen M. Tobacco industry marketing: an analysis of direct mail coupons and giveaways. Tob Control 2015;24:505-8.

46 Gilmore $A B$, Tavakoly $B$, Taylor $G$, et al. Understanding tobacco industry pricing strategy and whether it undermines tobacco tax policy: the example of the UK cigarette market. Addiction 2013;108:1317-26.

47 Institute of Medicine. Assessing the use of agent-based models for tobacco regulation. Washington DC: The National Academies Press, 2015.

48 Luke DA, Stamatakis KA. Systems science methods in public health: dynamics, networks, and agents. Annu Rev Public Health 2012;33:357-76. 